\title{
Techno-Economic Feasibility Study of Investigation of Renewable Energy System for Rural Electrification in South Algeria
}

\author{
Lower cost for better environment
}

\author{
Faycal Chermat \\ Automatic Laboratory of Setif, \\ Electrical Engineering \\ Department, Ferhat Abbas \\ University, Setif, Algeria \\ chermat33@yahoo.fr
}

\author{
Mabrouk Khemliche \\ Automatic Laboratory of Setif, \\ Electrical Engineering \\ Department, Ferhat Abbas \\ University, Setif, Algeria \\ mabroukkhemliche@yahoo.fr
}

\author{
Abdessalam Badoud \\ Electrical Engineering \\ Department, Ferhat Abbas \\ University, Setif, Algeria \\ badoudabde@yahoo.fr
}

Automatic Laboratory of Setif, Automatic Laboratory of Setif,

\author{
Samia Latreche \\ Electrical Engineering \\ Department, Ferhat Abbas \\ University, Setif, Algeria \\ ksamia2002@yahoo.fr
}

\begin{abstract}
This work aims to consider the combination of different technologies regarding energy production and management with four possible configurations. We present an energy management algorithm to detect the best design and the best configuration from the combination of different sources. This combination allows us to produce the necessary electrical energy for supplying habitation without interruption. A comparative study is conducted among the different combinations on the basis of the cost of energy, diesel consumption, diesel price, capital cost, replacement cost, operation, and maintenance cost and greenhouse gas emission. Sensitivity analysis is also performed.
\end{abstract}

Keywords-renewable energy; energy management; technoeconomic; feasibility study; optimization

\section{INTRODUCTION}

It is preferable to use renewable energy for cost reduction in rural areas where population growth is not proportional to the extension of the electricity grid [1]. This has paved the way for research on the use of autonomous renewable energies and on hybrid systems [2] by combining several types of power generation to reduce fuel consumption and therefore minimize operating cost [3]. However, prior to any implementation of a renewable energy system, a technical and economic feasibility study is necessary to justify the investment and allocated budget. Several studies have discussed the sizing and economic analysis of hybrid systems. An optimal sizing procedure of the wind/PV/diesel hybrid system was introduced in [4]. This procedure has been designed for small applications in Turkey. A techno-economic feasibility study of a house in Urumqi in China fuelled with $100 \%$ renewable energy was developed in [5]. The effect of the introduction of a wind farm for the improvement of the dynamic economic dispatching of the western Algerian network was studied in [6].

Authors in [7] and [8] established models for the components of a hybrid wind-powered solar-pumped storage power system. Authors in [9] presented an analysis of PV/wind hybrid systems for the power supply of a house, farm or enterprise, which demonstrated that these two sources could be independent or connected to the electrical grid with complex interactions. This complete hybridisation study has been considered expensive and laborious for many industrial technology departments. Authors in [10] designed a $100 \%$ costeffective system with low cost of energy (COE) by studying an FM transmitter station powered by a PV/diesel hybrid system for rural communities. HOMER software was used in [11] to study the techno-economic feasibility of a PV/diesel/battery hybrid system for the power supply of the Bin Habbas Town in Saudi Arabia. By analysing the solar radiation of Rafha, the storage in batteries increased with the penetration of renewable energies, and the hours of the diesel generator (DG) operation were reduced.

\section{METHODOLOGY}

\section{A. Location and Load Demand Specification}

This work is the first study about the center of Sahara, namely the town of In Salah, which is located in an altitude of $268 \mathrm{~m}$ between the coordinates of $2^{\circ} 28^{\prime} \mathrm{E}$ longitude and $27^{\circ} 12^{\prime} \mathrm{N}$ latitude. The study is conducted on a habitation that requires $57 \mathrm{kWh} /$ day. Figure 1 presents the average daily consumption.

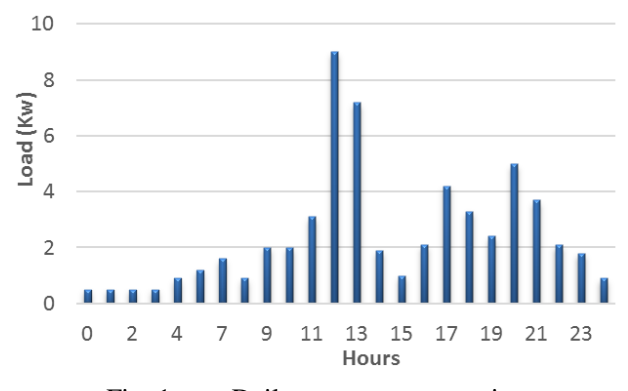

Fig. 1. Daily energy consumption. 


\section{B. Meteorological Data}

Requirements are obtained through NASA's site of meteorological surfaces and solar energy. Figures 2 and 3 show the global horizontal radiation and wind speed at In Salah, respectively. The average annual solar irradiance is $5.83 \mathrm{kWh} / \mathrm{m}^{2} /$ day, and the average wind speed is $5.1 \mathrm{~m} / \mathrm{s}$.

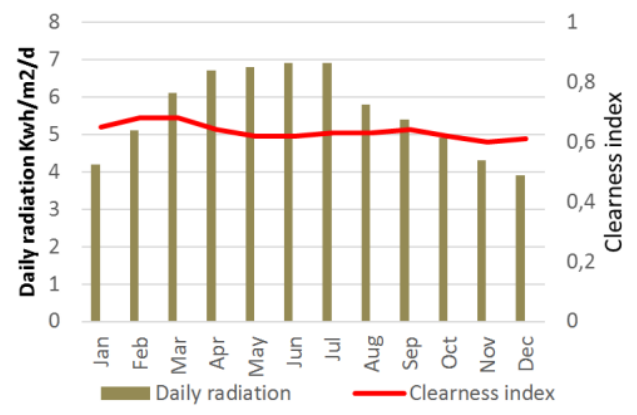

Fig. 2. Global horizonta radiation for In Salah.

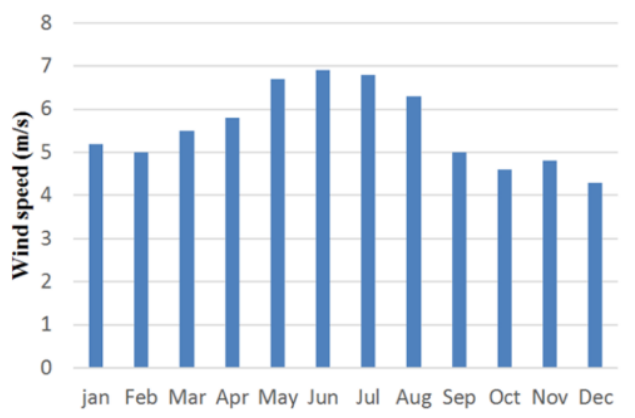

Fig. 3. Wind speed for In Salah.

\section{Evaluation Criteria}

Our study covers net percent cost (NPC) of the system, including investment or initial capital cost (ICC), replacement cost (RC), and operating and maintenance cost (OMC), fuel cost (FC), and the COE. NPC is given by (1):

$$
N P C=\frac{C_{t o t}}{C R F\left(i, T_{p}\right)}
$$

where Ctot is the total annualized cost of the system (\$/year), $i$ is the annual real interest rate $(\%), T p$ is the project lifetime, and $C R F$ is the capital recovery factor, which is calculated in the following equation [12]:

$$
C R F=\frac{i(1+i)^{n}}{(1+i)^{n}-1}
$$

where $i$ is the real interest rate and $\mathrm{n}$ is the number of years. $C O E$ is calculated from the following equation:

$$
C O E=\frac{C_{t o t}}{E_{\text {tot }}}
$$

where Etot represents the total consumption of electricity during the year (kWh/year). The fraction of PV energy and wind energy can be calculated as [13]:

$$
f_{p v}=\frac{E_{p v}}{E_{p v}+E_{W G}}
$$

$$
f_{W G}=\frac{E_{W G}}{E_{p v}+E_{W G}}
$$

\section{Energy Monitoring}

Energy management is defined according to ISO50001 as a "set of interrelated or interacting elements to establish an energy policy and energy objectives and process and procedures to achieve those objectives" [14]. An energy management algorithm is elaborated to explain the operation of the chosen hybrid system which satisfies the demand while taking into account the economic criteria described above. Its flow chart is shown in Figure 4 and its steps are:

If $P_{w}>P_{\text {load }}$ then the load is alimented directly from the wind generator.

Else we calculate $P_{p v}$

If $P_{p v}>P_{\text {load }}$ then we alimented by the GPV.

Else we calculate $P_{w}+P_{p v}$

If $P_{w}+P_{p v}>P_{\text {load }}$ then we powered directly from renewable resources.

Else we check $S O C$

If $S O C>40 \%$ then we aliment the load by extracting the lack from batteries.

Else return to DG and fill the gap from renewable resources and in the same time charge the batteries.

If $S O C>95 \%$ then the DG is extinguished and the load is supplied by filling the mast from the batteries.

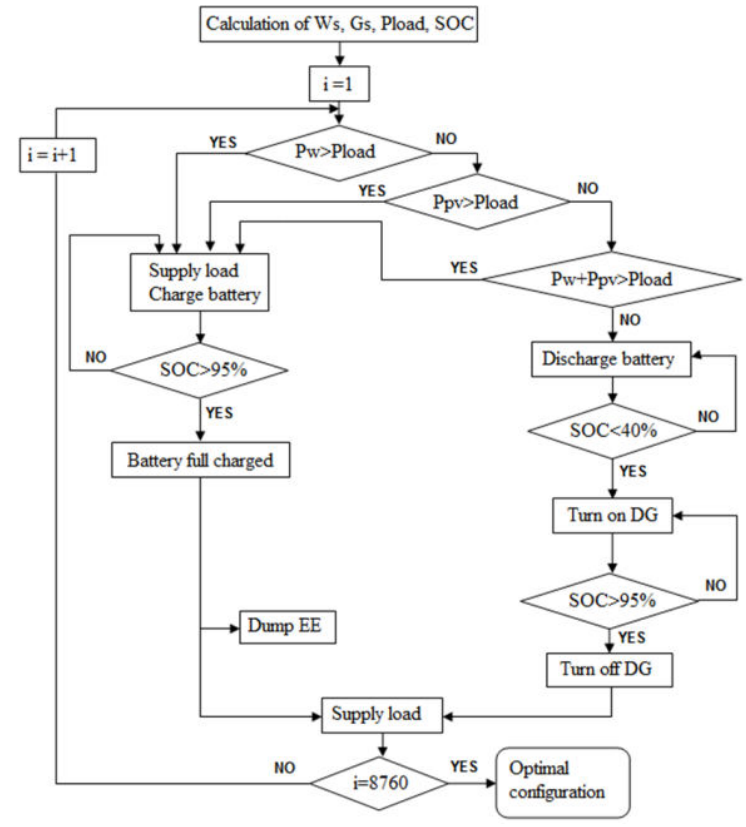

Fig. 4. Flow chart of energy management.

\section{SYSTEM COMPONENTS}

Figure 5 shows our proposed hybrid system. The load demand is coupled to the AC bus, whereas the wind generator, GPV and batteries are connected to the DC bus. A conventional backup DG is typically used to supplement the renewable 
system for maximum loads and during periods of poor resource generation.

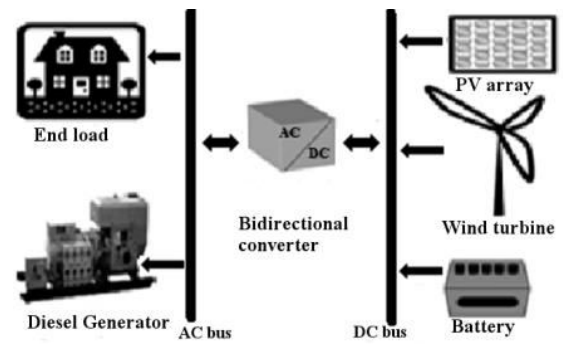

Fig. 5. Hybrid system design.

\section{A. PV System}

The electrical power produced by the photovoltaic network is calculated using (6):

$$
P_{p}=f_{p v} \times Y_{p v}\left(\frac{I_{t}}{I_{s}}\right)
$$

where $f p v, Y p v, I t$ and $I s$ are respectively the reduction factor, the total installed capacity, the solar radiation and the incident radiation at the standard test conditions.

\section{B. Wind System}

The mean power produced by an aerodynamic generator is given by [15]:

$$
P_{w}=\int_{V_{\text {in }}}^{V_{\text {out }}} P(v) f(v) d(v)
$$

where Vin is the wind speed at which electricity production starts, Vout the wind speed at which electricity production stops, $P(v)$ is the aero-generator's power curve (given by the manufacturer) and $f(v)$ is the Weibull probability density function.

\section{Power Converter}

The energy flows between AC and DC components are maintained thanks to the use of an energy converter which converts the DC into AC for the supply of several devices and plays the role of a "controller" for the direct current conversion of the PV generator into direct current.

\section{Battery}

The capacity of the storage unit expressed in ampere-hours is defined as follows:

$$
C_{B}=\frac{N_{j a} \times B_{j p}}{P_{D^{\times R}}}
$$

where Nja is the number of days of the storage unit autonomy, $B_{j p}$ is the daily requirement of the consumer expressed in (Ah) and it is deduced from the energy requirement in (Wh) and the chosen voltage of the batteries, $P_{D}$ is the maximum discharge depth of the storage unit and $R_{t}$ is the temperature correction factor [16]. The state of batteries charge can be calculated according to (9):

$$
\operatorname{SOC}(t+\Delta t)=\operatorname{SOC}(t)+\eta_{\text {bat }}\left(P_{B}(t) / V_{\text {bus }}\right) \Delta t
$$

where $\eta_{b a t}$ is equal to the round-trip efficiency in the charging process and is equal to $100 \%$ in the discharging process [17],
$V_{\text {bus }}$ is the DC bus voltage and $\Delta t$ is the hourly time step, set equal to $1 \mathrm{~h}$.

\section{E. Diesel Generator}

Currently, the price of diesel in Algeria is 0.21\$/1, having seen a $65 \%$ increase in a period of 4 years. The diesel generator operates according to constraint (10) [18]:

$$
P_{1}^{\min } \leq P_{1} \leq P_{1}^{\max }
$$

\section{RESULTS AND DISCUSSION}

The different configurations of the optimized systems are compared with different criteria, such as total NPC (TNPC), $\mathrm{COE}$, and energy production. Obtained results for each

\begin{tabular}{|c|c|c|c|c|}
\hline Configuration & Case 1 & Case 2 & Case 3 & Case 4 \\
\hline GD & 14 & 10 & 10 & 10 \\
\hline Converter & 0 & 15 & 15 & 15 \\
\hline Battery & 0 & 36 & 32 & 32 \\
\hline PV & 0 & 13.8 & 0 & 6.9 \\
\hline Wind & 0 & 0 & 3 & 2 \\
\hline \multicolumn{5}{|c|}{ Production kWh/year } \\
\hline Electricity & 74043 & 28389 & 29900 & 29686 \\
\hline Excess electricity & 53140 & 2513 & 3960 & 4381 \\
\hline Capacity shortage & 0.1 & 0 & 0 & 0 \\
\hline Unmet load & 5.1 & 0.0000309 & 0.0000606 & 0.0000708 \\
\hline \multicolumn{5}{|c|}{ Cost $(\$)$} \\
\hline Total net present cost $\$$ & 229361 & 78593 & 76762 & 73880 \\
\hline $\begin{array}{l}\text { Leveled cost of energy } \\
\$ / \mathrm{kwh}\end{array}$ & 0.858 & 0.294 & 0.287 & 0.276 \\
\hline O\&M cost $\$ / y r$ & 89576 & 18105 & 25021 & 19951 \\
\hline \multicolumn{5}{|c|}{ Generator \& Fuel } \\
\hline Hours of operation & 8759 & 361 & 1019 & 290 \\
\hline Fuel consumption $1 / \mathrm{yr}$ & 44330 & 1523 & 4365 & 1212 \\
\hline \multicolumn{5}{|c|}{ Emissions Kg/yr } \\
\hline Carbon dioxide $\left(\mathrm{CO}_{2}\right)$ & 116735 & 4012 & 11495 & 3190 \\
\hline Carbon monoxide & 288 & 9.9 & 28.4 & 7.88 \\
\hline Unburned hydocarbon & 31.9 & 1.1 & 3.14 & 0.872 \\
\hline $\begin{array}{l}\text { Particulate matter } \\
\text { Sulphur }\end{array}$ & 21.7 & 0.747 & 2.14 & 0.594 \\
\hline Sulphur dioxide & 234 & 8.06 & 23.1 & 6.41 \\
\hline Dioxide Nitrogen oxide & 2571 & 88.4 & 253 & 70.3 \\
\hline
\end{tabular}
configuration are presented in Table I. The Table is organized to encompass all the criteria necessary for the comparison in choosing the best configuration that meets our specifications.

TABLE I. CONFIGURATIONS COMPARATIVE STUDY

\section{A. Optimization Results}

The wind/PV/DG hybrid system (Case 4) comprises a design of $6.9 \mathrm{~kW}$ provided by the GPV, $6 \mathrm{~kW}$ of wind turbine represented by two $500 \mathrm{~W}$ generator types, a storage system that contains 8 strings mounted in parallel, each string containing 4 batteries connected in series, a $15 \mathrm{~kW}$ power converter, and a $10 \mathrm{~kW}$ DG. Case 4 is the most economical system with a low TNPC of $\$ 73880$, which accounts for $67.8 \%$ reduction of the DG system's TNPC (Case 1), 6\% reduction of the PV/DG system (Case 2) and $3.75 \%$ reduction of the wind/DG system (Case 3). Optimum COE produced by our system is $\$ 0.276$. Our system is the cheapest configuration, and has an energy production of $29686 \mathrm{kWh} /$ year, in which $43 \%$ is delivered by the GPV and $50 \%$ is provided by the supplied wind generator. The remaining energy production will be 
guaranteed by the DG, which generates $2159 \mathrm{kWh} /$ year instead of $74043 \mathrm{kWh} /$ year, in case the system is used alone, whereas for AC primary load, the generation is near $21000 \mathrm{~kW} /$ year. HOMER calculates the unmet load and its fraction by determining the ratio between the unmet loads and the annual electrical demand. For all our cases, the system can serve an electrical load that meets the demand. Therefore, the unmet load is negligible and tends to be zero. Figure 6 shows the monthly distribution of electricity produced in $\mathrm{kW}$ by all cases and confirms that energy production is dependent on meteorological data. Notably, DG does not produce a considerable amount of energy during the months that strong winds and solar potential allow the production of a large amount of energy from renewable sources. The production is the opposite for the other months. For example, December is the least sunny month with low wind speed, thereby providing low power output from the GPV and wind generator.

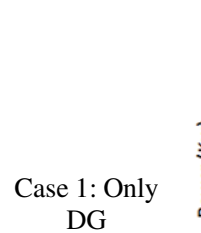

DG

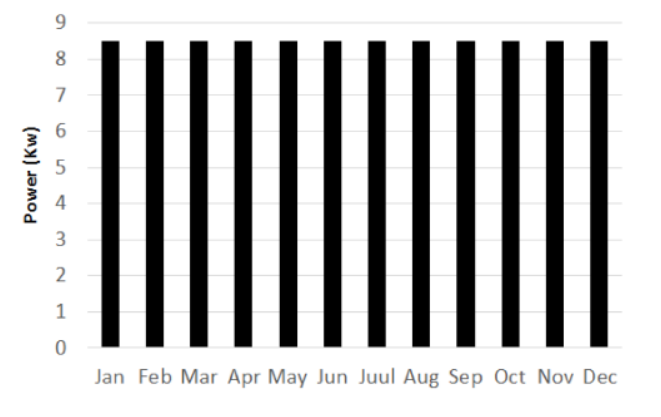

Case 2: PV/DG

Case 3: Wind/DG

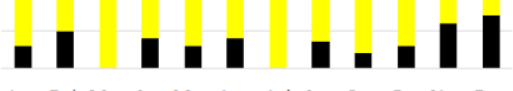

Jan Feb Mar Apr May Jun Jul Aug Sep Oct Nov Dec
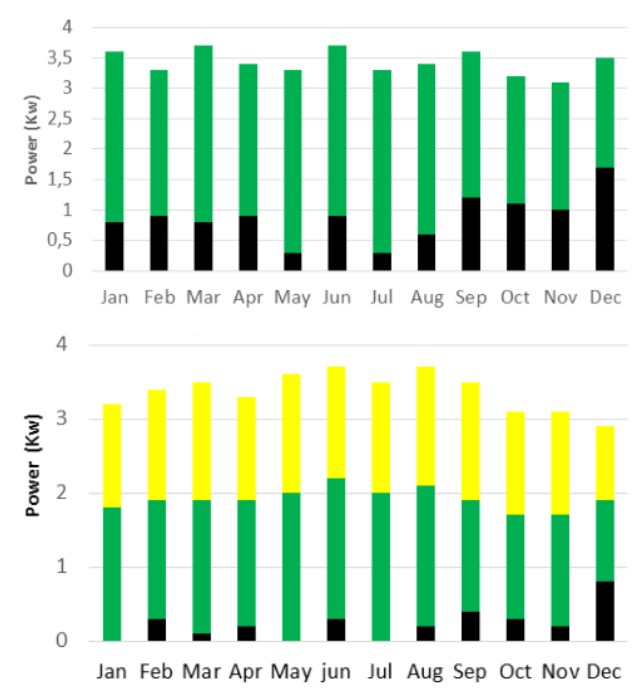

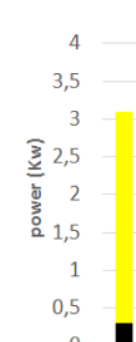

Fig. 6. Monthly average electric production of 4 cases. Black: DG, yellow: PV, green: wind.
At this level, the efficiency of our system is illustrated in Figure 7. If energy is lacking and the batteries are discharged, then GD intervenes, otherwise, it turns off, once the batteries are charged.

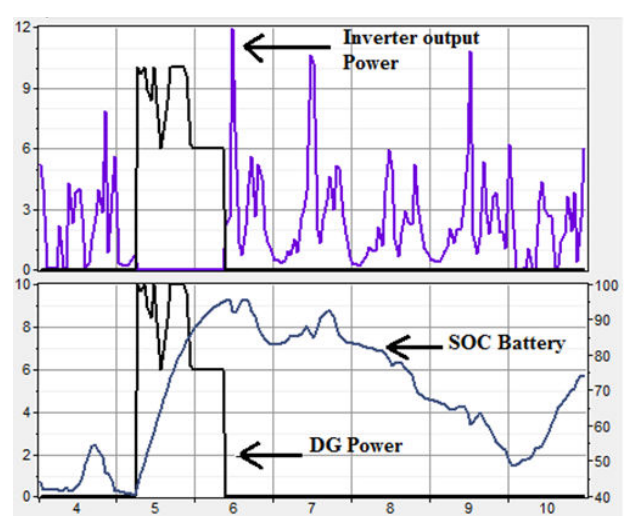

Fig. 7. Efficiency of the best hybrid system.

The selected hybrid system has a capacity shortage equal to zero and an excess electricity of $4381 \mathrm{kWh} /$ year that will be stored in the batteries. Figure 8 shows the cash flow summary on the basis of the costs for the best configuration. The ICC of our hybrid system is $\$ 43664$. It is the highest and accounts for more than $59.1 \%$ of the TNPC due to the prices of each subsystem. The remainder is distributed as follows: $14.1 \%$ is the $\mathrm{RC}, 27 \%$ is the $\mathrm{OMC}$ and the remaining $4.4 \%$ is the price of diesel consumption with electricity saving of almost $4.6 \%$.

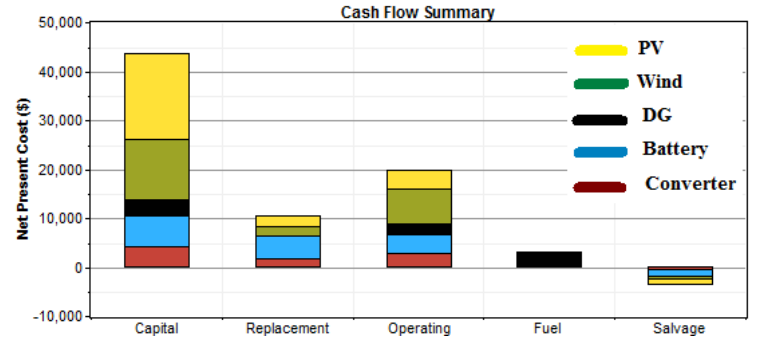

Fig. 8. Cash flow summary based on cost.

Table II shows the percentage of each cost on the basis of the NPC of all configurations. The use of fossil resources is initially inexpensive, although it requires money during operation. The integration of one or more sources of renewable energy production requires an expensive ICC but with a considerable reduction in operating budget and FC.

TABLE II.

DISTRIBUTION OF COSTS RELATIVE TO TNPC

\begin{tabular}{|c|c|c|c|c|c|c|}
\hline Costs & ICC & RC & OM C & Fuel & Salvage & TNPC \\
\hline $\mathbf{( \$ )}$ & $\mathbf{( \$ )}$ & $\mathbf{( \$ )}$ & $\mathbf{( \$ )}$ & $\mathbf{( \$ )}$ & $\mathbf{( \$ )}$ & $\mathbf{( \$ )}$ \\
\hline \multirow{2}{*}{ Case1 } & 4500 & 16497 & 89576 & 119004 & -215 & \multirow{2}{*}{229361} \\
\cline { 2 - 7 } & $2 \%$ & $7.2 \%$ & $39 \%$ & $51.9 \%$ & $0.1 \%$ & \\
\hline \multirow{2}{*}{ Case2 } & 49414 & 11412 & 18105 & 4090 & -4428 & \multirow{2}{*}{78593} \\
\cline { 2 - 7 } & $62.8 \%$ & $14.5 \%$ & $23 \%$ & $5.2 \%$ & $5.5 \%$ & \\
\hline \multirow{2}{*}{ Case 3 } & 32464 & 9860 & 25021 & 11718 & -2302 & \multirow{2}{*}{76762} \\
\cline { 2 - 7 } & $42.3 \%$ & $12.8 \%$ & $32.6 \%$ & $15.2 \%$ & $2.9 \%$ & \\
\hline \multirow{2}{*}{ Case4 } & 43664 & 10439 & 19951 & 3252 & -3427 & \multirow{2}{*}{73880} \\
\cline { 2 - 6 } & $59.1 \%$ & $14.1 \%$ & $27 \%$ & $4.4 \%$ & $4.6 \%$ & \\
\hline
\end{tabular}


The TNPC decreases from one scenario to another whilst adding renewable energy resources. In our hybrid system, we invested nine times the ICC of a conventional installation with a major optimisation of more than $97 \%$ of diesel consumption by reducing it to $1212 \mathrm{~L} /$ year whilst limiting the hours of operation of the DG to only 290 . This investment is successful because the addition of $\$ 39164$ for the ICC of the hybrid system benefits us from the savings of more than $\$ 115752$ regarding the diesel consumption throughout the project lifetime.

\section{B. Emissions}

The use of renewable energy sources not only has an economical but also an environmental impact. It is beneficial for the protection of the environment, the climate, the planet, and our health. One of the most important factors for climate change due to greenhouse gas emissions is carbon dioxide $\left(\mathrm{CO}_{2}\right) . \quad \mathrm{CO}_{2}$ is reduced to $3190 \mathrm{~kg} /$ year instead of $116735 \mathrm{~kg} /$ year when using the DG only, which accounts for $97.3 \%$ reduction with a fraction of renewable energy of $93 \%$. We can avoid injecting $2838625 \mathrm{~kg}$ of $\mathrm{CO}_{2}$ in a period of 25 years, which is the lifetime of our hybrid system, thereby decreasing all other air pollutants with the same percentage of 97.3\%.

\section{Sensitivity Analysis}

This analysis provides information regarding if a particular system will be optimal to certain criteria whilst relying on economic study and eliminating impossible systems. In our case, wind speed $(4-7 \mathrm{~m} / \mathrm{s})$, solar irradiation $\left(4-7 \mathrm{kWh} / \mathrm{m}^{2} / \mathrm{d}\right)$, height of windmill gauge $(15 \mathrm{~m}$ and $20 \mathrm{~m})$ and diesel price $(\$ 0.21-\$ 0.40)$ are our sensitivity variables. We aim to identify the effects of these changes on $\mathrm{CO}_{2}$ emissions. Figure 9 shows the optimal system by fixing the solar irradiation at $5.83 \mathrm{kWh} / \mathrm{m}^{2} /$ day and the wind speed at $5.1 \mathrm{~m} / \mathrm{s}$.

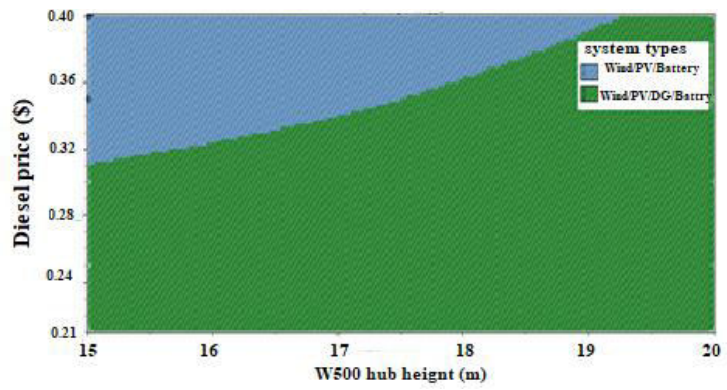

Fig. 9. Optimal system for fixed solar radiation and wind speed.

Notably, the proposed system is economically feasible for any height of the gauge, as long as the diesel price is less than $\$ 0.3$. At $\$ 3.5$, the wind/PV/battery system is most feasible, economically and environmentally with zero pollution. By fixing the diesel price at $\$ 0.21$ and the height of windmill gauge at $15 \mathrm{~m}$, we obtain the results shown in Figure 10 . Notably, the PV/DG/battery system is the least expensive under conditions where wind speed is less than $4.4 \mathrm{~m} / \mathrm{s}$ and solar irradiation is between $5.1 \mathrm{kWh} / \mathrm{m}^{2} /$ day and $6 \mathrm{kWh} / \mathrm{m}^{2} /$ day. The $\mathrm{PV} /$ battery system is the optimal solution for low wind speed and solar irradiation of more than $6 \mathrm{kWh} / \mathrm{m}^{2} /$ day with zero emissions. The wind/PV/DG hybrid system is economically feasible for proportional increases in meteorological data. However, the wind/DG/battery system will be feasible only by increasing the wind speed to more than $5 \mathrm{~m} / \mathrm{s}$ and decreasing the solar irradiation by less than $6 \mathrm{kWh} / \mathrm{m}^{2} /$ day.

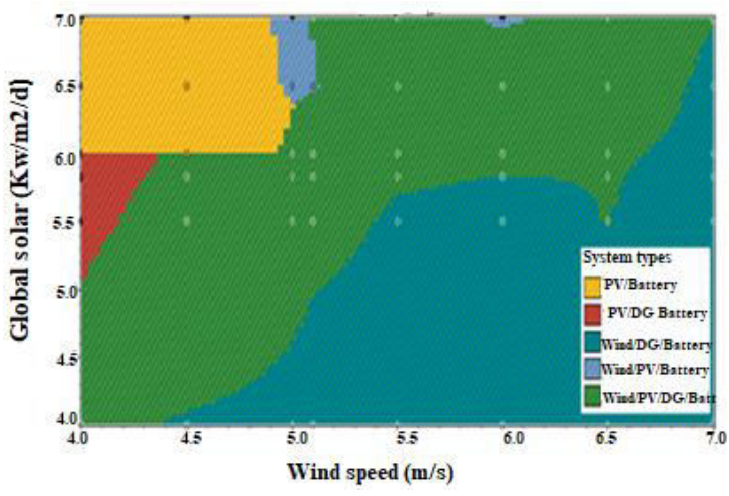

Fig. 10. Optimal system for fixed diesel price and hub height

Figure 11 shows the surface plot for $\mathrm{CO}_{2}$ emissions. $\mathrm{CO}_{2}$ emission rises when DG intervenes. The emission decreases with the increase in meteorological data. The increase in wind speed decreases $\mathrm{CO}_{2}$ emissions. However, emission does not occur when the solar irradiation reaches $6.4 \mathrm{kWh} / \mathrm{m}^{2} /$ day even with extremely low wind speed. Hence, in our system, the solar energy contributes more effectively than the wind energy from the environmental perspective.

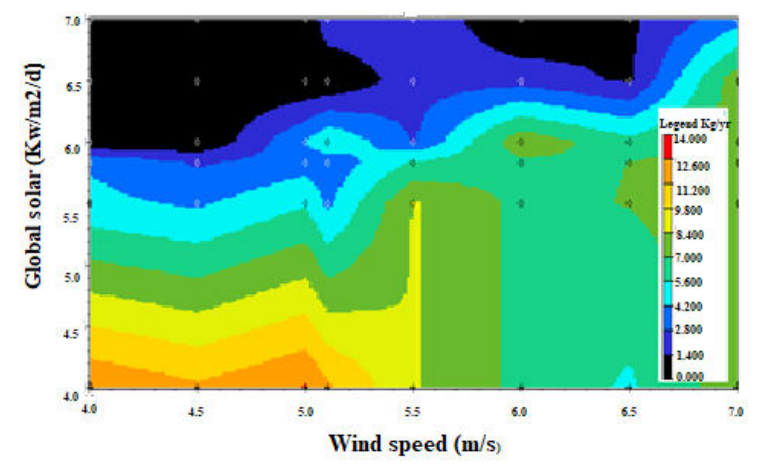

Fig. 11. Surface plot for $\mathrm{CO} 2$ emissions.

\section{CONCUSIONS}

In this work, we investigated several configurations of energy resources. The use of a single source is not economically or environmentally feasible. Hence, the use of two renewable energy sources, wind and PV coupled with a DG, is the optimum configuration. A new energy management algorithm was demonstrated, and shows how HOMER minimizes the DG operation, improves the energy efficiency of our system and increases the renewable fraction. We concluded with a feasibility study that has four defined sensitivity variables. We obtained the following satisfactory results:

- The increase in the price of diesel increases TNPC and $\mathrm{COE}$, and the increase of the height of the wind generator increases the penetration of wind energy. 
- The wind/PV/diesel hybrid system is economically feasible for proportional increases in meteorological data.

- The wind/DG/battery system requires high wind speed, whereas the PV/diesel system is the optimum solution for low wind speed.

- Increasing wind speed reduces $\mathrm{CO}_{2}$ emissions. However, emissions do not occur when the solar irradiation reaches a certain level even with an extremely low wind speed. Thus, in our system, the solar energy contributes more efficiently than wind energy from an environmental perspective.

- Using renewable energy sources with DG, battery storage supply, and sharing the load by adapting the current system seems to be the most applicable solution for today's conditions.

\section{APPENDIX}

Technical \& Economical Parameters of Hybrid System

- PV system

Rated power: $230 \mathrm{~W}$

Capital cost: $580 \$$

Replacement cost: $230 \$$

OMC: $100 \$$

- Wind system

Rated power: $3 \mathrm{~kW}$ DC

Life cycle: 15 years

Starting wind speed: $3.5 \mathrm{~m} / \mathrm{s}$

Capital cost: 6200\$

Replacement cost: $2100 \$$

OMC: $280 \$ / y r$

- Bidirectional converter

Capital cost: 4250 \$

Replacement cost: $4250 \$$

OMC: $215 \$ / y r$

Efficiency: $90 \%$

Rectifier efficiency: $85 \%$

Rectifier capacity: $100 \%$

\section{- Battery}

Nominal voltage (V): 6V

Maximum capacity: $9645 \mathrm{Kwh}$

Capital cost: $200 \$$

Lifetime: $1168 \mathrm{Ah}$

Maximum charge current: $41 \mathrm{~A}$

- Diesel generator

Diesel price: $0.21 \$$

\section{REFERENCES}

[1] J. Byrne, B. Shen, B. Wallace, "The economics of sustainable energy for rural development: A study of renewable energy in China", Energy Policy, Vol. 26, No. 1, pp. 45-54, 1998

[2] J. Dekker, M. Nthontho, S. Chowdhury, S. P. Chowdhury, "Economic analysis of PV/diesel hybrid power systems in different climatic zones of South Africa", International Journal of Electrical Power and Energy Systems, Vol. 40, No. 1, pp. 104-112, 2012

[3] R. Sebastian, "Modelling and simulation of a high penetration wind diesel system with battery energy storage", International Journal of Electrical Power \& Energy Systems, Vol. 33, No. 3, pp. 767-774, 2011

[4] O. Ekren, B. Y. Ekren, B. Ozerdem, "Break-even analysis and size optimization of a PV/wind hybrid energy conversion system with battery storage-a case study", Applied Energy, Vol. 86, No. 7, pp. 1043-1054, 2009

[5] C. Li, X. Ge, Y. Zheng, C. Xu, Y. Ren, C. Song, C. Yang, "Technoeconomic feasibility study of autonomous hybrid wind/PV/battery power system for a household in Urumqi, China”, Energy, Vol. 55, pp. 263272,2013

[6] A. Belmadani, L. Benasla, M. Rahli, "Amelioration d'un dispatching economique dynamique par l'introduction d'une ferme eolienne. Application au reseau electrique ouest algerien", Revue Roumaine des Sciences Techniques-Serie Electrotechnique et Energetique, Vol. 57, No. 3, pp. 269-280, 2012 (in French)

[7] R. Yan, L. Yanpin, "Simulation and optimization of hybrid wind-solarpumped-storage power system", IEEE International Conference on Electric Information and Control Engineering, Wuhan, China, April 1517, 2011

[8] Y. Ren, Y. Zheng, Y. P. Li, J. J. Huang, D. Zhang, "Modelling and optimization of hybrid wind/PV pumped-storage power system", Applied Mechanics and Materials, Vol. 48-49, pp. 693-696, 2011

[9] J. B. V. Subrahmanyam, P. Alluvada, Bandana, K. Bhanupriya, C. Shashidhar, "Renewable energy systems: Developement and perspectives of a hybrid solar-wind system", Engineering, Technology \& Applied Science Research, Vol. 2, No. 1, 2012, pp. 177-181, 2012

[10] M. Moghavvemi, M. S. Ismail, B. Murali, S. S. Yang, A. Attaran, S. Moghavvemi, "Development and optimization of a PV/diesel hybrid supply system for remote controlled commercial large scale FM transmitters", Energy Conversion and Management Vol. 75, pp. 542551,2013

[11] M. Shaahid, I. El Amin, "Techno-economic evaluation of off-grid hybrid photovoltaic-diesel-battery power systems for rural electrification in Saudi Arabia-A way forward for sustainable development", Renewable and Sustainable Energy Reviews, Vol. 13, No. 3, pp. 625-633, 2009

[12] G. J. Dalton, D. A. Lockington, T. E. Baldock, "Feasibility analysis of renewable energy supply options for a grid-connected large hotel", Renewable Energy, Vol. 34, No. 4, pp. 955-964, 2009

[13] A. N. Celik, "Optimisation and techno-economic analysis of autonomous photovoltaic-wind hybrid energy systems in comparison to single photovoltaic and wind systems", Energy Conversion and Management, Vol. 43, No. 18, pp. 2453-2468, 2002

[14] T. C. Seng, Energy Management and Economics, The instute of engineers \& Singapore and National Environment Agency, 2016

[15] R. Hammouche, Atlas Vent de l'Algerie, Office National de la Meteorologie, 1990 (in French)

[16] S. Diaf, M. Belhamel, M. Haddadi, A. Louche, "Technical and economic assessment of hybrid photovoltaic/wind system with battery storage in Corsica island", Energy Policy, Vol. 36, No. 2, pp.743-754, 2008

[17] R. Belfkira, L. Zhang, G. Barakat, "Optimal sizing study of hybrid wind/PV/diesel power generation unit", Solar Energy , Vol. 85, No. 1, pp. 100-110, 2011

[18] J. B. Fulzele, S. Dutt, "Optimium planning of hybrid renewable energy system using HOMER", International Journal of Electrical and Computer Engineering, Vol. 2, No. 1, pp. 68-74, 2012 